\title{
The Process of Biogas Production by Rice Straw
}

\author{
Tao Liu
}

School of North China Electric Power University, Hebei 071003, China

1303551336@qq.com

Keywords: Rice Straw, Pretreatment, Anaerobic Digestion, Process Control, Biogas Residue and Slurry

\begin{abstract}
China has a wealth of straw resources, rice straw accounted for a large part. The previous approach was to discard or burn the straw, causing a variety of environmental problems. In order to solve the problem of fecal pollution produced in the development of farms, we usually use rice straw to produce biogas at present. By producing biogas, these rice straw resources can be used effectively and comprehensively. Not only to solve environmental problems, but also to improve the farmers' income. In this paper, the specific process flow of rice straw production was introduced in the aspects of rice straw pretreatment, anaerobic digestion, biogas slurry treatment and process control.
\end{abstract}

\section{Introduction}

At present, many farms use the method of burning to deal with rice straw, and the process will release ammonia, hydrogen sulfide and other irritating odor of gas, which will not only adversely affect the environment, but also waste resources [1]. Biogas technology solves the problem of straw problem with less pollution matter and smaller odor, and productions of biogas systems can be widely used.

According to statistics, in the UK, the use of organic waste, which produces methane through the microbial anaerobic digestion, can replace the UK 25\% consumption of the gas [2]. The construction of large and medium-sized farms biogas projects, therefore, can improve the biogas process and protect environment.

\section{The Process of Biogas Production in Rice Straw:}

The process flow chart is as follows:

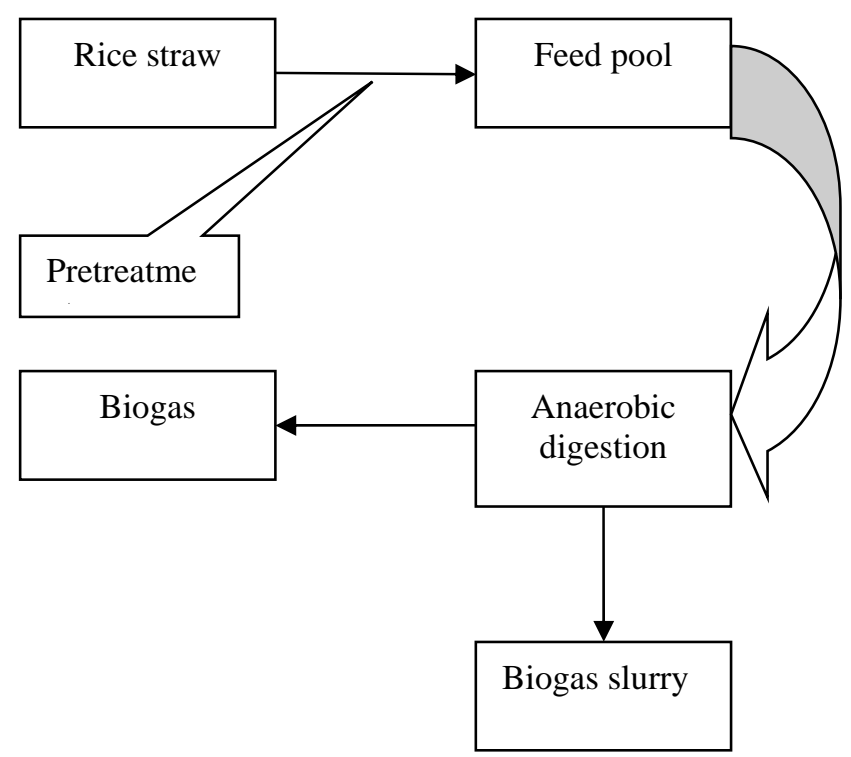

Fig.1 Biogas process 


\section{Specific Process}

A complete large and medium-sized biogas fermentation project must include these processes: raw material collection, pretreatment, biogas digesters, post-treatment, biogas purification and storage [3]. we can see from the Fig.1.

\subsection{Raw Materials}

We buy straw from farmers and can be stored locally, that is, small distribution storage stations. It can also be concentrated to large storage and stop stations, because of easy management and processing.

\subsection{Pretreatment}

Broken process: According to the needs of fermented rice rod length, the rice rod should be cut or crushed to a certain size, usually about $3 \mathrm{~cm}$. And then according to the amount of rice per cubic meter of biogas digesters, we must add water for mixing and wetting for some time to soften.

Stir the raw material: Straw, bacteria and carbon ammonia is mixed in a certain proportion, after mixing the bacteria and carbon ammonia in water, Sprinkling mixed water while turning the already wetted straw.

Fermentation: The wet straw should be put in a certain way. Leave voids at the top and sides of the stack, such as holes, cracks, etc. The pile is covered with plastic sheets, there are wooden pallets between the bottom of pile and ground. We should pay attention to control the retting time in composting, if the piling time is too short, the degradation of lignocelluloses in the straw is not enough. we must control the retting time, generally 3-4 days in the summer, winter 4-6 days. When the temperature reaches a certain value, and the straw becomes soft, White hyphens appear, the retting basically completed [4].

\subsection{Anaerobic Digestion Technique}

\subsubsection{The Principle of Anaerobic Digestion}

At present, China mainly uses dry fermentation technology, the principle of it is the same as that of normal biogas fermentation. They use methane producing bacteria and non methane producing microorganisms to convert organic matter into methane and carbon dioxide under certain moisture, temperature and anaerobic conditions. Anaerobic fermentation also includes three stages, which are hydrolysis stage, acidification stage and methanogenic reaction stage.

During the first stage of liquefaction, insoluble cellulose in straw is converted into soluble compounds; in the second stage of the acid producing stage, soluble compounds are then converted to shorter chains of acids and ethanol by fungi; in the third stage of methane production, these products become methane mixtures by various anaerobic methanogenic bacteria, which are mainly methane and carbon dioxide gas.

\subsubsection{Basic Conditions for Biogas Production}

For large biogas projects, multiple digesters, which are series connection with each other, are required. In biogas digesters, we need to ensure the appropriate conditions, which is beneficial to the growth and reproduction of methanogens. That is, the appropriate temperature, fermentation broth concentration, $\mathrm{C} / \mathrm{N}$ ratio, ratio of acid to alkali, bacteria and anaerobic environment [5]. Part of the above parameters reference value is shown in Table.1

Table 1. Fermentation parameters reference

\begin{tabular}{|c|c|}
\hline Name & value \\
\hline Fermentation temperature & $30{ }^{\circ} \mathrm{C}-45^{\circ} \mathrm{C}$ \\
\hline C/N ratio & $20: 1-30: 1$ \\
\hline \multirow{3}{*}{ Feed concentration } & $10 \%-15 \%$ in spring \\
\cline { 2 - 2 } & $8 \%-9 \%$ in summer \\
\cline { 2 - 2 } & $15 \%-20 \%$ in winter \\
\hline PH & $7-8.5$ \\
\hline
\end{tabular}

(1) The gas tightness of biogas digesters must be guaranteed. In the process of producing methane by organic fermentation, the dominant anaerobic bacteria need strict anaerobic treatment.

(2) The raw materials can enter into the fermentation tank after retting pretreatment. 


\subsubsection{Evaluation and Measurement of Biogas Fermentation Process}

General total solids (TS), suspended solids (VSS), volatile solids (VS) and volatile suspended solids (VSS), chemical oxygen demand (COD) and biological oxygen demand (BOD) index are used to evaluate and measure the raw materials Organic matter content and biogas content.

The main factors determining the functional characteristics of anaerobic digesters are the hydraulic retention period (HRT), the solids retention period (SRT) and the microbial retention period (MRT).

\subsection{Treatment and Utilization of Biogas Residue}

Biogas fermentation is not only a process of producing biogas resources, but also a process of making fertilizer. The solid residue can be directly used as fertilizer in soil or ponds. At the same time, biogas slurry is rich in nitrogen, phosphorus, potassium, sodium, calcium and other nutrients. These products can be used to fish, pigs, cattle, some control of crop pests by discharging in the aeration tank, oxidation pond aerobic treatment equipment and has a broad prospect of comprehensive utilization.

\section{Conclusion}

Rice straw is used as raw material to produce methane. The raw material source is abundant and widely distributed. The process flow is simple, the equipment investment is little, no other non polluting pollutants are produced, and the efficient utilization of straw can be realized. This method has solved the environmental pollution problems caused by burning and discarding large amounts of straw in our country. It can also increase the income of rural areas in China and promote the construction of rice stem biogas on a large scale and a large scale.

\section{References}

[1]. Amon, T., Jeremic, D., Boxberger, J., 2001. Neue Entwicklungen der landwirtschaftlichen Biogaserzeugung in Österreich. In: Freyer, B. (Ed.). Wissenschaftstagung zum ökologischen Landbau, vol. 6, 6-8 März 2001. Freising Weihenstephan/Deutschland, pp. 465-468.

[2]. Aili, Y. Kejun, Z. Yaoxin, F. Guoyuan. Study and design on a high performance biogas project treating chicken manure. Biogas Forum, 2 (1991), pp. 14-19.

[3]. R.C. Anand, R. Singh A simple technique: charcoal coating around the digester improves biogas production in winter Bioresour. Technol., 45 (1993), pp. 151-152.

[4]. Shao Mingsheng. Study on the technological conditions of anaerobic fermentation of rice straw. [D]. Wuhan: Hubei University of Technology, 2009.

[5]. I. Angelidaki, L. Ellegaard, B.K. Ahring A mathematical model for dynamic simulation of anaerobic digestion of complex substrates: focusing on ammonia inhibition Biotechnol. Bioeng., 42 (1993), pp. 159-166. 